\title{
Adventitial inversion in the distal anastomosis in surgical treatment of acute DeBakey type I aortic dissection
}

\author{
Tirone E. David, MD
}

\footnotetext{
From the Division of Cardiovascular Surgery, Peter Munk Cardiac Centre, Toronto General Hospital, University of Toronto, Toronto, Ontario, Canada.

Disclosures: Author has nothing to disclose with regard to commercial support.

Received for publication Jan 10, 2016; accepted for publication Jan 15, 2016; available ahead of print Feb 10, 2016.

Address for reprints: Tirone E. David, MD, 200 Elizabeth St 4N453, Toronto, ON M5G 2C4, Canada (E-mail: tirone.david@uhn.ca).

J Thorac Cardiovasc Surg 2016;151:1346-7

$0022-5223 / \$ 36.00$

Copyright $(2) 2016$ by The American Association for Thoracic Surgery

http://dx.doi.org/10.1016/j.jtcvs.2016.01.028
}

Oda and colleagues ${ }^{1}$ from Osaka, Japan, have published an interesting study on the technique of the distal anastomosis during the surgical treatment of acute DeBakey type I aortic dissection and its potential effect in promoting thrombosis of the false lumen in this issue of the Journal. Those investigators reviewed 90 patients who underwent "hemiarch replacement" with 2 different techniques of distal anastomosis: adventitial inversion into the true lumen (group A, 36 patients) and sandwich technique with strips of polytetrafluoroethylene felt inside the intima and on the outside of the adventitia of the dissected aorta (group S, 54 patients). The technique of adventitia inversion was originally described by Floten and associates, ${ }^{2}$ and I used it a couple of times but didn't think much of it. Now, however, I have to reevaluate this technical aspect of the distal anastomosis in acute DeBakey type I aortic dissection. Our Japanese colleagues showed that the false lumen was thrombosed in $78.8 \%$ of patients in group A and $47.9 \%$ in group B among 81 survivors who were evaluated by computed tomographic scan before hospital discharge. One-year survival was higher in the first group (94.6\% vs $80.1 \%$ ), but the difference did not reach statistical significance, probably because of small sample size.

I have a few comments about this retrospective study. Firstly, Oda and colleagues ${ }^{1}$ are to be congratulated for their excellent results in these 90 patients. With a mean age of 73.1 years, their patients were older than in other series, including those from large registries of acute type A aortic dissections, and they were just as sick if not sicker than in most, with 22 patients with evidence of malperfusion, 21 in shock, and 12 with cardiac arrest. These are complex cardiovascular problems to manage surgically, and yet the operative mortality was only $10 \%$. Oda and colleagues ${ }^{1}$ stated that "extracorporeal circulation was instituted by placement of arterial cannulae in the femoral and right axillary artery," and the reader has to assume that this was done in all cases, which if so is a unique technical aspect of their operations, because most of us use the femoral or the axillary artery for arterial return. Next, they stated that "no aortic clamps were used" and

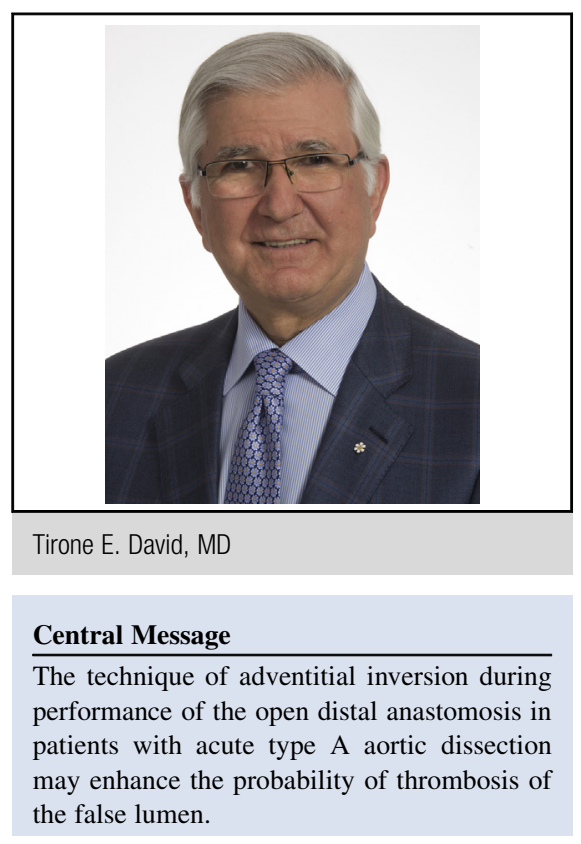

See Article page 1340 .

that "the primary tear was resected whether in the ascending aorta or transverse arch." Once the distal anastomosis was completed under circulatory arrest, "the arterial cannula was shifted to the prosthetic graft and (antegrade) cardiopulmonary bypass was reconstituted." My own group described this open anastomosis technique and antegrade perfusion after completion of the distal anastomosis several years ago. ${ }^{3}$ Our rationale was to reduce bleeding from the distal anastomosis and increase the probability of thrombosis of the false lumen; however, postoperative thrombosis of the false lumen was documented in only $41 \%$ of our patients. ${ }^{4}$ Oda and colleagues ${ }^{1}$ reported a $78.8 \%$ occlusion of the false lumen among 34 operative survivors who underwent the technique of adventitial inversion. If they are correct, the message is that this technique, in addition to the open anastomosis and antegrade perfusion after completion of the distal anastomosis, markedly increases the rate of false-lumen thrombosis and consequently increases patients' long term survival. I don't know whether this finding will be reproducible by other investigators, because distal tears are common in patients with acute DeBakey type I aortic dissections, ${ }^{5}$ particularly in younger patients because of the common association of aortic dissection with genetic syndromes that often have advanced degenerative changes of the arterial media. There is no harm in using this 
technique, however, and it may reduce the risk of bleeding at the distal anastomosis. We thank Oda and colleagues ${ }^{1}$ for bringing to our attention a potentially very useful technique that was originally described 20 years ago. ${ }^{2}$

\section{References}

1. Oda T, Minatoya K, Sasaki H, Tanaka H, Seike Y, Itonaga T, et al. Adventitial inversion technique for type A aortic dissection distal anastomosis. J Thoracic Cardiovasc Surg. 2016;151:1340-5.
2. Floten HS, Ravichandran PS, Furnary AP, Gately HL, Starr A. Adventitia inversion technique in repair of aortic dissection. Ann Thorac Surg. 1995; 59:771-2.

3. David TE. Surgery for acute type A aortic dissection. J Thorac Cardiovasc Surg. 2015;150:279-83.

4. David TE, Armstrong S, Ivanov J, Barnard S. Surgery for acute type A aortic dissection. Ann Thorac Surg. 1999;67:1999-2001; discussion 2014-9.

5. Van Arsdell GS, David TE, Butany J. Autopsies in acute type A aortic dissection. Surgical implications. Circulation. 1998;98(19 Suppl):II299-302; discussion II302-4. 